\title{
SÍMBOLOS E RITUAIS DO FUTEBOL ESPETÁCULO: uma análise das emoções no campo de jogo
}

\author{
Ana Raquel Mendes dos Santos' \\ Talita Grazielle Pires de Corvalho² \\ Priscilla Pinto Costa da Silva ${ }^{3}$ \\ Maritza Lordsleem Silva ${ }^{4}$ \\ Clara Maria Silvestre Monteiro de Freitas ${ }^{5}$
}

\section{RESUMO}

Objetivou-se identificar e analisar os símbolos e rituais dos torcedores do futebol pernambucano, com o propósito de elucidar as emoções presentes na vivência deste fenômeno. Trata-se de uma pesquisa descritiva de campo com abordagem quantiqualitativa envolvendo 142 torcedores do Sport, Santa Cruz e Náutico ${ }^{6}$. Utilizou-se um roteiro de entrevista semiestruturada e um roteiro de observação. As entrevistas foram analisadas por meio da análise de conteúdo. Os resultados mostraram a mascote (Sport) e as cores (Santa Cruz e Náutico) como os símbolos mais representativos. Os rituais presentes antes, durante e após o espetáculo futebolístico foram: oração, comportamentos de festividades/práticas supersticiosas, consumo de álcool e torcer/comemorar. A análise deste cenário permitiu discutir sentimentos e emoções que estão presentes para vivenciar o fenômeno, assim como levantar novas discussões no campo sociocultural da Educação Física.

Palavras-chave: Simbolismo. Comportamento Ritualístico. Futebol. Emoções.

1 Doutoranda em Educação Física. Universidade de Pernambuco (UPE). Recife/Pernambuco, Brasil. E-mail: raquel_mdss@hotmail.com

2 Mestre em Educação Física. Universidade de Pernambuco (UPE). Recife/Pernambuco, Brasil. E-mail: talitagpires@hotmail.com

3 Doutora em Educação Física. Professora da Universidade Federal do Rio Grande do Norte (UFRN). Natal, Rio Grande do Norte, Brasil. E-mail: laprisci@gmail.com

4 Doutoranda em Educação Física. Universidade de Pernambuco (UPE). Recife/ Pernambuco, Brasil. E-mail: maritzalordsleem@hotmail.com

5 Doutora em Educação Física. Professora da Universidade de Pernambuco (UPE). Recife/ Pernambuco, Brasil. E-mail: clarasilvestre@uol.com.br

6 Apoio financeiro: Coordenação de Aperfeiçoamento de Pessoal de Nível Superior. Conflito de interesses: Não há conflito de interesses.

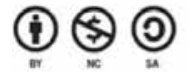




\title{
SYMBOLS AND RITUALS FOOTBALL SPECTACLE: an analysis of the emotions in the
} playing field

\begin{abstract}
The objective was to identify and analyze the symbols and rituals of football fans from Pernambuco, with the purpose of elucidating the emotions present in the experience of this phenomenon. This is a descriptive field research with a quantitative approach involving 142 Sport, Santa Cruz and Náutico fans. A semi-structured interview script and an observation script were used. The interviews were analyzed through content analysis. The results showed mascot (Sport) and colors (Santa Cruz and Náutico) as the most representative symbols. The rituals present before, during and after the soccer spectacle were: prayer, behavior of superstitious practices/practices, alcohol consumption and cheer/cheer. The analysis of this scenario allowed to discuss feelings and emotions that are present to experience the phenomenon, as well as to raise new discussions in the socio-cultural field of Physical Education.
\end{abstract}

Keywords: Symbolism. Ceremonial behavior. Soccer. Emotions.

\section{SÍMBOLOS Y RITUALES DE FÚTBOL ESPECTÁCULO: un análisis de las emociones en el campo del juego}

\section{RESUMEN}

Se objetivó identificar y analizar los símbolos y rituales de los aficionados del fútbol pernambucano, con el propósito de elucidar las emociones presentes en la vivencia de este fenómeno. Se trata de una investigación descriptiva de campo con enfoque cuantitativo que involucra a 142 aficionados del Sport, Santa Cruz y Náutico. Se utilizó un guión de entrevista semiestructurada y un guión de observación. Las entrevistas se analizaron mediante el análisis de contenido. Los resultados mostraron la mascota (Sport) y los colores (Santa Cruz y Náutico) como los símbolos más representativos. Los rituales presentes antes, durante y después del espectáculo futbolístico fueron: oración, comportamientos de festividades/prácticas supersticiosas, consumo de alcohol y torcer/ conmemoración. El análisis de este escenario permitió discutir sentimientos y emociones que están presentes para vivir el fenómeno, así como levantar nuevas discusiones en el campo sociocultural de la Educación Física.

Palabras clave: Simbolismo. Conducta ceremonial. Fútbol. Emociones. 


\section{INTRODUÇÃO}

O futebol é um dos principais fenômenos socioculturais do século XXI, considerado, hoje, um grande espetáculo esportivo capaz de movimentar e reunir milhões de pessoas. Esta espetacularização transformou o futebol em um "pseudomundo à parte" (DEBORD, 2003), criado não apenas para ser jogado, mas também para ser contemplado como uma imagem suscetível à espetacularização. Assim, o futebol espetáculo apresenta-se como um evento de entretenimento grandioso para a sociedade.

Atualmente, acredita-se que o espetáculo futebolístico possui características inerentes à religiosidade (ELIADE, 2008; ELIAS; DUNNING, 1992). Sobre esta afirmação, Elias e Dunning (1992) relatam que a efervescência coletiva provocada nos rituais religiosos pode ser comparada com a emoção e o excitamento presentes nos esportes modernos. O futebol apresenta um significado quase ou totalmente religioso por ter se transformado em uma das principais fontes de identificação, significação e gratificação dos envolvidos com o fenômeno. Isto se deve ao fato de o campo esportivo ser mediado por espetáculos coletivos realizados a partir de disputas que envolvem manifestações, dramas, danças, músicas, cerimônias, símbolos e rituais.

O futebol se apresenta como uma atividade que envolve comportamentos, expressões faciais e gestuais, além de abranger uma simbologia associada à esfera ritualística e espiritualista, constituindo-se, assim, como um espetáculo capaz de mobilizar diversas emoções. Nos momentos dos jogos, é comum, por exemplo, visualizar torcedores reverenciando os símbolos dos times, as cores e as mascotes, adorando seus ídolos e heróis, além de exteriorizarem seus sentimentos através de cantos, gritos, choros e orações. O que se percebe é que eles vivenciam aquele momento como se estivessem em um templo sagrado. De acordo com Le Breton (2009), a emoção é fundamental para a existência do homem no mundo. E isto ocorre de maneira efetiva a partir do momento em que os gestos e as palavras conseguem se materializar através da emoção.

Esta ligação de afetividade entre o time e o torcedor foi construída, criada e incorporada pelos sujeitos ao longo da existência deste esporte, e incentivada, principalmente, pelos meios de comunicação que se apropriaram da gestão em torno dos jogos (ALVES et al., 2016; BONIN et al., 2016). O estudo de Origuela e Silva (2015) acrescenta que nos momentos em que esses torcedores se reúnem para assistir aos jogos de futebol, sendo no interior dos estádios ou em qualquer outro ambiente, há uma identificação com o time, independente da classe social ou econômica. Dito por outras palavras, estes sujeitos se reúnem com a mesma paixão na esperança de ver seu time sair como vencedor.

Todos os aspectos citados são inseparáveis do futebol espetáculo e, dentre eles, podemos considerar que os símbolos presentes entre os torcedores são dramatizados em rituais exibindo, per si, distintas maneiras de manifestações coletivas presentes no campo de jogo. Sobre os símbolos, Eliade (1991) ressalta que o pensamento simbólico é consubstancial ao ser humano e antecede a linguagem e a razão discursiva. Para o autor, o termo "símbolo" se refere a tudo aquilo que, de maneira generalizada ou análoga, representa alguma coisa ou alguém. Portanto, os símbolos indicam uma realidade sensível que possui 
um significado transcendente. Eles são capazes de revelar aspectos da realidade humana por meio de significados específicos, preenchendo determinada função. No futebol, os símbolos estão presentes a partir do momento em que os indivíduos conseguem se comunicar com uma linguagem única e subjetiva. São nos estádios que as disputas acontecem e é neste local que os torcedores compartilham dos símbolos comuns nessa prática esportiva.

Sobre esta questão, o estudo de Simões e Conceição (2004) revelou que o futebol é preenchido por conteúdos simbólicos associados à esfera ritualística, capazes de mobilizar emoções peculiares no universo do espetáculo esportivo. Neste contexto,, os símbolos do futebol podem estar associados às questões de pertencimento ao grupo por meio dos uniformes, cores, mascotes, brasão, bandeiras, enfeites, entres outros elementos que manipulam o imaginário dos integrantes de um mesmo clube. Ao mesmo tempo, os gestos e expressões faciais, também presentes no campo esportivo, podem indicar mensagens simbólicas de alegria pelo gol marcado ou pela vitória da partida, raiva pela derrota, entre outras emoções.

Em relação aos rituais, Segalen (2002, p. 31) explica que estes são caracterizados por "atos formalizados, expressivos, portadores de uma dimensão simbólica". Ou seja, os rituais se apoiam em símbolos reconhecidos pela coletividade e estão relacionados a um conjunto de comportamentos codificados por mensagens corporais, verbais, gestuais e/ou comportamentais, com caráter repetitivo e forte carga simbólica para os atores e testemunhas. No futebol, as torcidas possuem seus símbolos e rituais, bem como as características próprias de torcer, que vão desde a preparação para assistir aos jogos do time até as crenças e superstições criadas. A investigação de Lima, Moura e Antunes (2015), centrada no aspecto citado, apresentou os símbolos que identificavam as torcidas e sua forma de ritualização no estádio. Este estudo apontou que a torcida mantinha as superstições a partir de orações, uso contínuo da mesma vestimenta, ocupação dos mesmos lugares no estádio, utilização de amuletos da sorte, dentre outros comportamentos ritualísticos.

A par desse quadro conjecturado, é importante ressaltar que a compreensão dos símbolos e rituais presentes no futebol permite uma análise valiosa no campo de investigação da área sociocultural da Educação Física, pois dada a importância deste fenômeno no mundo, em especial na sociedade brasileira, a discussão sobre esta temática proporciona um entendimento sobre o comportamento dos sujeitos e das relações sociais presentes em torno deste esporte. Mesmo sabendo que o futebol tem se tornado um objeto de análise sociocultural no Brasil nos últimos tempos (SOUZA, MARCHI JÚNIOR, 2017), esta investigação teve a intenção de interpretar uma realidade ainda pouco estudada no campo do futebol pernambucano, a partir da análise dos sentimentos e emoções que estão presentes entre os torcedores em relação ao seu time, bem como a tudo que ele representa. Além disso, acredita-se que a compreensão do fenômeno proposto pode auxiliar na criação de estratégias de enfrentamento de alguns problemas existentes, como, por exemplo, a violência no futebol, que hoje se configura como um dos grandes desafios existentes não apenas no Estado de Pernambuco, como também em toda a sociedade brasileira. Portanto, este estudo objetivou identificar e analisar os símbolos e rituais dos torcedores do futebol pernambucano, com o propósito de elucidar as emoções que estão presentes na vivência deste fenômeno. 


\section{PROCEDIMENTOS METODOLÓGICOS}

Esta pesquisa trata-se de uma investigação interpretativa descritiva de campo, com abordagem quantiqualitativa (BANKS, 2009; MINAYO, 2007), que envolveu 142 torcedores dos três principais clubes de futebol de Pernambuco: o Sport, Santa Cruz e Náutico. Os clubes foram escolhidos em razão da popularidade que eles representam no Estado de Pernambuco e da quantidade de títulos conquistados em campeonatos nacionais, inter-regionais, regionais e estaduais. A seleção dos sujeitos foi intencional e baseada no critério de saturação dos dados, que, segundo Fontanella, Ricas e Turato (2008), estabelece ou define o tamanho final da amostra, interrompendo a captação de novos participantes. Foram incluídos os torcedores do Sport, Santa Cruz e Náutico que frequentavam os estádios em dias de jogos, com idade igual ou superior a 18 anos, sem restrição de sexo, escolaridade e que aceitassem participar da pesquisa. Excluíram-se torcedores que não residiam em Pernambuco, por acreditar que estes não conseguem vivenciar com frequência o fenômeno nos estádios quando comparados aos que residem no Estado.

Como instrumentos foram utilizados um roteiro de entrevista semiestruturada, que contemplou dados sociodemográficos (para caracterizar os sujeitos investigados) e questões pertinentes ao tema estudado; e um roteiro de observação proposto por Spradley (1980), que descreve as situações sociais ao longo de nove dimensões, tais como: espaço, ator, atividade, objeto, ato, evento, tempo, objetivo e sentimento. Vale ressaltar que a observação não-participante foi empregada pelo fato de o pesquisador conseguir observar uma determinada realidade, sem integrar-se a ela (MARCONI; LAKATOS, 2010).

A coleta de dados iniciou-se no segundo semestre de 2015 durante o Campeonato Brasileiro de Futebol. As entrevistas semiestruturadas aconteceram nos momentos que antecederam as partidas de futebol e foram realizadas na área externa dos estádios e no interior deles (cadeiras/arquibancadas). Os sujeitos convidados a participar do estudo foram apresentados aos objetivos da pesquisa. As entrevistas duraram cerca de 15 a 20 minutos. Para melhor veracidade das falas dos participantes, utilizou-se um aparelho gravador. Concomitantemente à realização das entrevistas, o pesquisador observou 12 jogos, sendo 4 jogos de cada time. Como recurso para registro das atividades/informações foi utilizada uma câmera digital para armazenar fotografias e filmagens.

A análise descritiva dos dados incluiu a distribuição de frequências (absolutas e relativas) dos dados relacionadas ao perfil sociodemográfico, utilizando o programa SPSS 10.0 para Windows. As entrevistas semiestruturadas foram transcritas e submetidas à análise de conteúdo, utilizando a técnica de análise categorial e obedecendo aos seguintes passos: 1. Construção do corpus de análise a partir da transcrição do material coletado nas entrevistas; 2 . Leitura flutuante para familiarização com os conteúdos do material coletado; 3. Definição e identificação das unidades de registros no texto; 4. Nomeação e identificação das unidades de significação; 5. Quantificação das unidades de significação em cada corpus; 6. Agrupamento dos temas para construção das categorias; 7. Nomeação, quantificação e descrição das categorias; e 8. Associação das categorias às características dos entrevistados e ao conhecimento científico existente (BARDIN, 2009). Em paralelo, as entrevistas foram 
associadas às informações adquiridas durante a observação não-participante para, assim, promover um diálogo entre as informações apuradas. Após esta fase, utilizou-se o software GoDiagram Express versão 2.6.2 para a construção dos diagramas que representaram as categorias analíticas investigadas.

Este projeto de pesquisa foi submetido e aprovado pelo Comitê de Ética em Pesquisa com Seres Humanos da Universidade de Pernambuco sob o CAEE: 9584614.5.0000.5207. Todas as diretrizes estabelecidas nas resoluções 466/12 do Conselho Nacional de Saúde/ MS foram observadas, visando assegurar os direitos e deveres que dizem respeito à comunidade cientifica, ao(s) sujeito(s) e ao Estado. Todos os participantes assinaram o Termo de Consentimento Livre e Esclarecido.

\section{RESULTADOS E DISCUSSÃO}

Dos 142 torcedores entrevistados, 49 eram do Sport, 49 do Santa Cruz e 44 do Náutico. A maioria destes era sócio dos seus clubes $(64,1 \%)$ e uma pequena parcela fazia parte da torcida organizada $(1,4 \%)$. Com o intuito de conhecer o perfil dos sujeitos entrevistados, foram coletados os dados sociodemográficos e observou-se que os torcedores tinham idade entre 18 e 80 anos. A maioria deles eram homens $(78,2 \%)$, casados $(52,8 \%)$, que moravam com a família $(70,4 \%)$, residiam em casas $(53,5 \%)$ e possuíam habitação própria $(81 \%)$. Além disso, 39,4\% possuíam ensino superior completo, parte significativa trabalhava $(78,2 \%)$ com carteira assinada $(42,3 \%)$ e recebia entre 3 e 6 salários mínimos $(28,9 \%)$. Um pouco mais da metade dos entrevistados consideravam ter cor da pele branca $(51,4 \%)$ e a maioria declarou seguir uma religião $(88 \%)$, sendo a religião católica a mais indicada (54,9\%).

Para discutir os dados das entrevistas, foram estabelecidas duas categorias analíticas a partir das respostas advindas dos entrevistados. A primeira, "Os símbolos do futebol espetáculo sob o olhar dos torcedores", que apresentou os símbolos mais indicados pelos torcedores; e a segunda, "Os rituais do futebol espetáculo sob o olhar dos torcedores", correspondendo aos rituais realizados antes, durante e após uma partida de futebol. Com $o$ intuito de diferenciar as falas das entrevistas dos torcedores, foram utilizadas as siglas $T_{s p}$ (Torcedor do Sport), $\mathrm{T}_{\mathrm{sc}}$ (Torcedor do Santa Cruz) e $\mathrm{T}_{\text {nau }}$ (Torcedor do Náutico).

\section{Os símbolos do futebol espetáculo sob o olhar dos torcedores}

Os símbolos de uma torcida de futebol representam a sua marca identitária. Ao serem escolhidos pelo clube, transformam-se em um sinal coletivo, estando seu significado referido não neles mesmos, mas nas várias associações que possam existir. Deste modo, os símbolos são projetados a partir dos sentimentos e valores significativos para as torcidas, partilhados por seus membros como sinais de distinção expressos em todo o material que produzem (TEIXEIRA, 2006). 
Nesta direção, no momento das entrevistas com os torcedores, foi realizado o seguinte questionamento: "Na sua opinião, quais os principais símbolos presentes no cenário do clube para o qual você torce?" Ao analisar as respostas, observou-se a indicação de diversos símbolos, como observado na figura 1, representados pelos balões brancos, expostos da extremidade superior a inferior de acordo com a frequência com que foram relatados pelos torcedores.

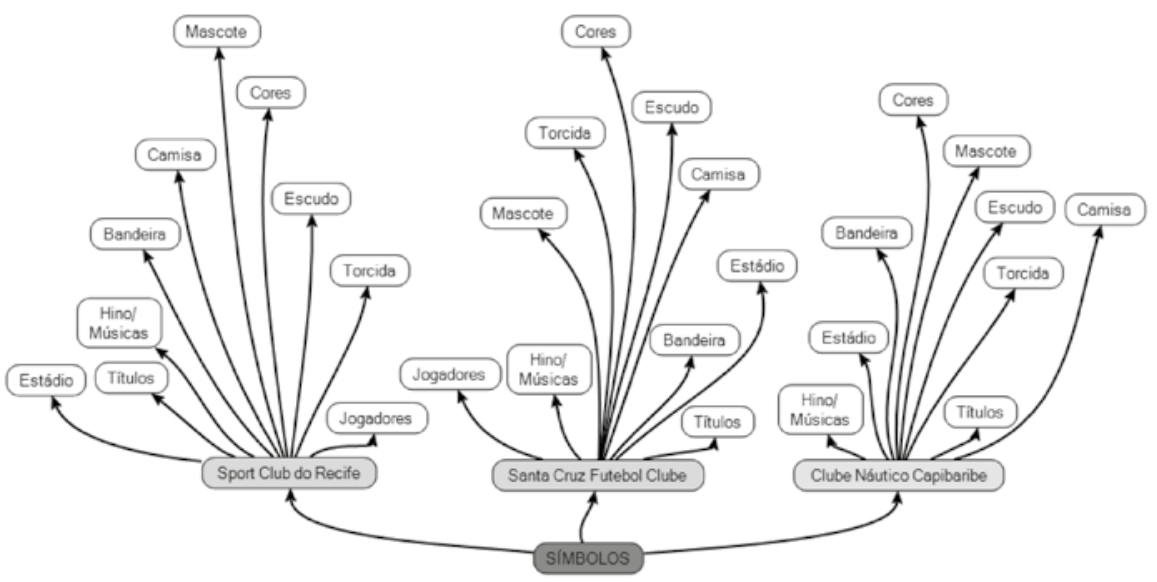

Entre os torcedores do Sport, a mascote foi o símbolo de maior destaque. Este é representado por um Leão, o animal mais forte e temido de toda a selva, como indicado nas falas a seguir:

[...] o leão é o rei da selva, um animal superior aos outros". $\left[\mathrm{T}_{\mathrm{sp}(6)}\right]$

"O leão é um desbravador, é um guerreiro, é um lutador, é um vencedor". [ $\left.\mathrm{T}_{\mathrm{sp}(41)}\right]$

A história ${ }^{7}$ da mascote do time é revelada a partir de uma disputa contra as equipes do Remo e do Paysandu, que ocorreu em 1919 na cidade de Belém do Pará (na época, região bastante desenvolvida no que diz respeito ao futebol), tendo como prêmio o troféu "Leão do Norte", representado por um leão de bronze. O Sport foi o campeão, deixando as equipes locais inconformadas com o resultado, ao ponto de se recusarem a entregar o troféu ao time Recifense. No entanto, o troféu foi trazido à força para Recife e, a partir daí, adotou-se o Leão como mascote símbolo do time rubro-negro. Diante do fato histórico apresentado, percebe-se a importância que o leão possui para os torcedores do Sport, tendo em vista que representa um animal que possui força e raça. Sobre isto, nas observações dos

7 FONTE: < http://www.sportrecife.com.br/especial107anos/sport_leao.cfm > . 
jogos nos estádios, havia sempre uma pessoa vestindo uma fantasia de leão e que estava presente nos gramados dos estádios, agitando os torcedores a cada partida e posando para fotos, principalmente com as crianças.

Vale salientar que muitos times brasileiros marcam a sua identidade por meio das mascotes, que, frequentemente, são representadas por personagens animais que se tornaram símbolos do clube. O estudo de Brandão et al. (2015) analisou as mascotes presentes em 627 times de futebol das cinco regiões brasileiras. Destes, 280 times possuíam mamíferos como mascotes símbolos, estando o Leão presente em 89 clubes, seguido pelo Tigre (37 times), Lobo (24 times), Raposa (15 times), Pantera (11 times) e Cachorro (9 times). De acordo com Queiroz (2005), as imagens de animais adotados pelos clubes acentuam o imaginário dos torcedores, principalmente os animais selvagens em detrimento dos domésticos. Os animais selvagens são astutos, audaciosos e predadores, capazes de impor força. Desta forma, há uma transferência de sentido a partir de uma percepção subjetiva ao se atribuir aos times, por meio da extensão metafórica, conceitos predominantes nos animais. Como afirma Duran (1997), o animal sempre fez parte da vida humana e a relação entre eles acontece espontaneamente. O simbolismo animal repercute nas atitudes do ser humano por meio do imaginário. Portanto, esses símbolos são capazes de evocar sentimentos e valores que animam a imaginação dos torcedores com visões que reafirmam a coesão coletiva desses sujeitos.

Ainda sobre a importância da mascote do Sport, foi observado durante os jogos nos estádios que muitos torcedores levavam consigo objetos que remetiam à figura do animal, como, por exemplo, leões de pelúcia. Ao indagar sobre esse costume, o $\mathrm{T}_{\mathrm{sp}(42)}$ explicou que

\footnotetext{
“Eu trago meus leõezinhos de pelúcia [...]. São três, é um meu, um da minha esposa e um da minha filha. A gente traz, entra no estádio com o leãozinho. Não é pra dar sorte, porque muitas vezes pensa que é mito, que é mística. Não... nada disso. É uma realização de festa mesmo. Eu venho fazer a festa. Cada jogo do Sport pra mim é uma festa".
}

Conforme podemos perceber no depoimento acima citado, a festa se faz presente nestes ambientes esportivos, visto que os estádios, em dias de jogos, se transformam em um local de festividade para toda a família. Os torcedores estão envolvidos por uma efervescência coletiva e se preparam para vivenciar uma celebração, vestindo suas melhores roupas, se ornamentando com acessórios nas cores dos times e levando consigo objetos que representam o clube, como, por exemplo, a mascote de pelúcia relatada na fala do torcedor. É interessante notar neste caso que o leão levado ao estádio pelo entrevistado não está ligado ao misticismo ou à crença de trazer sorte ao time, mas trata-se de um brinquedo, um objeto infantil que proporciona para ele e seus familiares uma forma de trazer alegria e festa dentro do estádio.

Para os torcedores do Santa Cruz e do Náutico, as cores dos times foram os símbolos mais representativos. Os torcedores do primeiro time são chamados de tricolores, pois possuem três cores significativas: preto, vermelho e branco. Cada cor possui uma definição distinta, como revelado pelos torcedores: 
"O preto, que representa a luta, o vermelho é o sangue e o branco é a paz". $\left[\mathrm{T}_{\mathrm{sc}(2)}\right]$

"As cores é a identidade do clube né? Quando você ver qualquer coisa vermelho, preto e branco, você se identifica mesmo sendo coisas que não tem nada a ver com o clube. Você identifica aquilo como uma coisa positiva em relação a você porque está identificado com o seu clube de coração". [ $\left.\mathrm{T}_{\mathrm{sc}(2)}\right]$

Já os torcedores do Clube Náutico Capibaribe são conhecidos como os alvirrubros, por possuírem o vermelho e o branco como suas cores padrão. Essas cores possuem significados que estão presentes até em momentos extracampo, como indicado nas falas a seguir:

"[...] vermelho que simboliza a luta, um time forte; e o branco de paz". [ $\left.\mathrm{T}_{\text {nau(34) }}\right]$

"É muito importante esse vermelho e branco pra mim. No meu dia a dia, eu procuro sempre fazê-las presente em minha vida $[\ldots]^{\prime \prime}$. $\left[\mathrm{T}_{\text {nau(13) }}\right]$

Nas observações dos jogos, foi identificado um torcedor símbolo do Náutico, conhecido como "Mister N". Este personagem costuma estar presente nos jogos do Náutico utilizando acessórios que fazem referência ao time, inclusive com o rosto pintado nas cores alvirrubras. Ao entrevistá-lo, ele revelou que

"Quando eu gosto de uma coisa do meu time querido, eu compro sempre. Um chaveiro, um boné, uma meia, tênis também vermelho e branco, tudo que for direcionado nas cores vermelho e branco, eu compro". [ $\left.\mathrm{T}_{\text {nau(26) }}\right]$

Sobre a história das cores do Náutico, o próprio artigo $4^{\circ}$ do estatuto do clube indica que o vermelho e o branco já se faziam presentes nos uniformes da equipe desde o primeiro esporte que originou o clube Náutico: o remo ${ }^{8}$. As cores são utilizadas como formas de representação de uma identidade clubística. De acordo com Andrade (2008), a composição de identidade visual de um time de futebol é constituída pelas bandeiras, escudo, camisa, calção, meias, mascote, entre outros. Todos esses itens e acessórios possuem as respectivas cores dos clubes. Assim, as escolhas das cores são significativas para a história do time e estas podem possuir diferentes origens, que vão desde a historicidade do clube até as relações místico-religiosas.

Sobre esta questão, Eliade (2011) explica que o símbolo é capaz de transmitir sua mensagem mesmo quando deixa de ser compreendido, uma vez que o símbolo é conduzido ao indivíduo integral e não apenas à sua inteligência. Diante desses aspectos, observa-se que as cores compõem a identidade visual de cada clube, direcionando muitas vezes o torcedor a consumir produtos com tais características. Muitas vezes, um torcedor rejeita comprar determinado objeto ou roupa porque possuem as cores dos times adversários.

8 FONTE: < http://www.nautico-pe.com.br/simbolos $>$. 
Neste caso, a identidade visual do produto ligado ao time é de extrema importância para quem está consumindo. Em suma, é principalmente nos estádios de futebol que se percebe a diversidade de símbolos capazes de materializar as várias maneiras de se comunicar no momento de torcer. Neste olhar, os jogos de futebol se transformaram em verdadeiros espetáculos que misturam festas e símbolos, com destaque para o efeito visual provocado pelos torcedores.

\section{Os rituais do futebol espetáculo sob o olhar dos torcedores}

Alguns campos sociais constituem um verdadeiro reservatório de ritual para os indivíduos. As atividades coletivas de forte intensidade emocional, como o futebol, por exemplo, preenchem o espaço contemporâneo de signos e rituais, oferecendo saídas para as obrigações regulamentadas do dia-a-dia, abrindo, neste sentido, espaço à integração e propondo ao imaginário social a escapatória de suas simbolizações (SEGALEN, 2002). Assim, no campo futebolístico observamos criações ritualísticas de slogans, superstições, comportamentos não habituais, cantos, roupas sagradas e acessórios indispensáveis, os quais representam os objetos de identificação, de simbolização e de ritualização dos torcedores. Neste estudo, os rituais do futebol presentes entre os torcedores foram identificados a partir da seguinte pergunta: "Você realiza algum ritual antes, durante e após assistir uma partida de futebol? Explique este(s) ritual(s)". A figura 2 revela os principais rituais (balões cinca claro) que estão presentes entre os torcedores de futebol, expostos da extremidade superior a inferior de acordo com a frequência em que foram relatados.

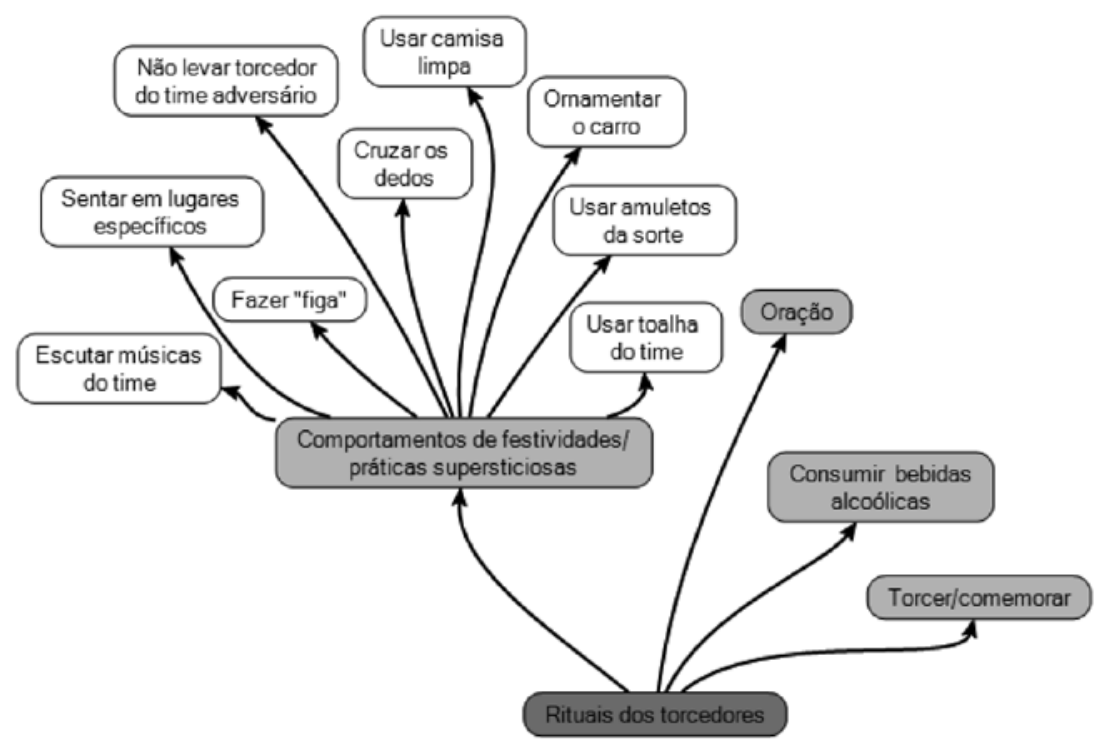


O ritual mais relatado pelos torcedores foi a "oração", que esteve presente antes, durante e após a partida de futebol, com distintas finalidades. Para os torcedores, a oração é realizada com a intenção de pedir proteção para si mesmo, para os demais torcedores, para os jogadores e para toda a equipe que faz parte do espetáculo futebolístico. Além disso, a oração é utilizada para pedir a Deus que o time consiga marcar um gol, como também para agradecer a vitória do time , como mencionado nas falas a seguir:

"[...] o meu ritual é agradecer a Deus a minha chegada até o campo. Eu me abasteço com o poder de Deus, peço proteção para meus amigos, para os conhecidos e até para os desconhecidos e pra que os nossos profissionais, juízes, jogadores, até pelos médicos, os policiais, que isso forma uma somatória desse conjunto todo. Que a gente tenha uma grande paz, tanto no início, no meio, como no final do jogo ne?". [ $\left.{ }_{\text {sc(47) }}\right]$

"Só fico pedindo a Deus lá na hora do jogo pra fazer gol". [ $\left.\mathrm{T}_{\mathrm{sc}(21)}\right]$

"As vezes a gente agradece ne? Agradece quando o resultado é positivo e quando é negativo a gente esquece". $\left[\mathrm{T}_{\text {nau(13) }}\right]$

"Se o time ganha, eu agradeço a Deus e faço o sinal da cruz". [ $\left.\mathrm{T}_{\mathrm{sc}(48)}\right]$

Esta postura religiosa revelada pelos torcedores também foi evidenciada no estudo de Machado (2005) que analisou a comunicação ritualística dos torcedores nos estádios. Os comportamentos dos torcedores relatados pelo autor foram similares às observações realizadas nos estádios e expostas no presente estudo. Quando, por exemplo, a bola não entrava na área do gol, o torcedor entrelaçava as mãos para suplicar ajuda a Deus; ou quando o jogador realizava um gol, os torcedores elevavam as mãos para o céu ou faziam o sinal da cruz simbolizando um agradecimento. Diante destes fatos, observou-se que os atores do ritual se utilizam de tais comportamentos religiosos para reforçar a crença de alcançar a vitória ou na tentativa de evitar a frustração da derrota.

Neste cenário, podemos observar que o futebol, assim como a religião, são instituições capazes de unir as pessoas, dando origem a um estado de êxtase emocional comparado ao da cerimônia religiosa (GIULIANOTTI, 2010). De acordo com Frange (2015), o futebol é celebrado para milhões de pessoas assim como o padre/pastor celebra a missa ou culto; e os jogadores buscam a vitória para satisfazer os torcedores da mesma maneira que o padre/pastor se utiliza da palavra para confortar os devotos sofredores. De fato, cada um desses eventos possui propósitos diferentes em sua essência, porém apresentam características particulares que podem ser equiparadas quando se trata da devoção e do fanatismo. Dentro ou fora do campo esportivo, inúmeras manifestações religiosas sempre estão presentes, não apenas entre os torcedores, mas também entre os atletas, a equipe técnica e demais atores sociais envolvidos neste cenário. Assim, pode-se considerar que os sujeitos envolvidos com o futebol procuram Deus ou qualquer outra divindade superior com o propósito de buscar força e conforto para vivenciar este fenômeno tão dinâmico e imprevisível. 
O segundo ritual mais indicado foram os "comportamentos de festividade/práticas supersticiosas" antes, durante e após uma partida de futebol, na tentativa de afirmar seu amor pelo time e/ou trazer sorte ao jogo. Em relação aos comportamentos de festividades, alguns torcedores revelaram que costumam ornamentar seu carro e escutar músicas do time quando estão à caminho do estádio, como indicado nos depoimentos seguir:

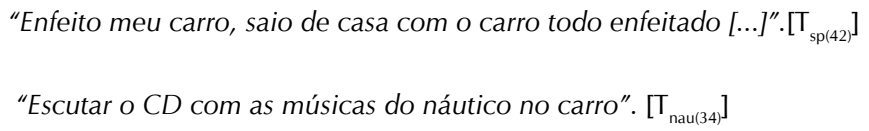

Estas práticas indicam uma maneira de se preparar para assistir a uma partida de futebol, como também para entrar no clima do jogo e fazer a festa. Estes comportamentos tão comuns no estado de Pernambuco servem para provocar os torcedores de times adversários, principalmente nos momentos que antecedem aos jogos. O grande problema é que muitos torcedores dos clubes concorrentes não entendem esta atitude como uma brincadeira ou como uma forma de festividade, aspecto que tem transformado estas situações em um campo de rivalidade entre torcedores de diferentes times.

No que se refere às práticas supersticiosas, os torcedores indicaram várias situações, dentre elas, à limpeza da camisa que vai ao estádio, o receio de estar acompanhado por um amigo de outro time e também o local específico em que assiste ao jogo, como mencionado nas falas a seguir:

"Eu sempre mantenho a camisa limpa, sempre lavada. Eu acho que atrapalha um pouco se tiver suja (risos)". [ $\left.\mathrm{T}_{\text {sp(40) }}\right]$

"[...] não levar amigo que seja do time adversário. Eu acho que levar gente de outro clube, que torce pra outro time, eu acho que influencia também em dar azar". $\left[\mathrm{T}_{\text {sp }(49)}\right]$

"Eu gosto de tá no lado esquerdo dele (seu pai). Eu acho meio estranho quando eu sento do lado oposto. Não sei porquê. Eu não me sinto bem [...]". [T $\left.{ }_{\text {nau(15) }}\right]$

Confiar nestas crenças supersticiosas relatadas anteriormente é uma forma de fazer com que os torcedores acreditem que estão afastando o azar e/ou trazendo a sorte a favor do seu time, tendo, com isso, a esperança de que nada de ruim irá acontecer. A crendice de realizar determinados gestos e de portar consigo objetos que consideram amuletos da sorte durante os jogos, como também de apresentarem determinados costumes que já estão incorporados naturalmente na rotina pós-jogo, apareceram como práticas supersticiosas, como indicado nas falas seguintes:

"Quando o time vai bater um escanteio, uma falta, eu faço logo uma figa e dá certo, costuma dá certo". $O T_{s p(11)}$ revelou que cruza os dedos para rezar: "[...] cruzo assim a mão, eu faço assim um estilo de uma reza, as vezes... dependendo do lance". [ $\left.\mathrm{T}_{\mathrm{sc}(34)}\right]$ 


\footnotetext{
"A única coisa que eu faço, se isso é ritual, é pegar os meus objetos que representam o santa cruz". [T $\left.\mathrm{sc}_{\mathrm{c}(49)}\right]$

"Eu tenho uma toalha do náutico, que toda vez que o náutico ganha, vou tomar banho e me enxugo com ela". [ $\left.T_{\text {nau(28) }}\right]$
}

Os comportamentos de festividades e as práticas supersticiosas presentes no esporte também foram analisados em outros estudos (DAMIANI, 2005; LIMA; MOURA; ANTUNES, 2015) que verificaram que estas práticas sempre fizeram parte da rotina, não apenas dos torcedores, mas também dos treinadores e atletas envolvidos no espetáculo esportivo. Le Breton (2009) exemplifica este cenário quando aponta o beijo, o abraço e o aperto de mão como condutas presentes nos rituais do universo esportivo, sendo estas oferecidas aos próximos como sinais de felicitaçaõ e/ou sorte. Dentre as condutas citadas destaca-se o beijo oferecido pelas rainhas aos vencedores de algumas modalidades, como ciclismo e maratona; o abraço ofertado pelos oficiais no instante em que são entregues as medalhas aos atletas campeões; e o aperto de mão como regra do golfe e no tênis. Le Breton elucida ainda que no futebol, após cada gol marcado, os membros da equipe do clube se aproximam uns dos outros para comemorar ou beijar o autor do tento. Observam-se ainda as imagens dos beijos frenéticos dados à taça conquistada pelos atletas de uma equipe campeã.

Deste modo, o futebol é um espetáculo que envolve rituais presentes em um espaço possuído pela ilusão e liminaridade, através de uma dinâmica que envolve elementos mágicos, religiosos e supersticiosos (DAOLIO, 2005; TURNER, 1974). Portanto, o espetáculo futebolístico funciona como uma espécie de linguagem ritualística fortemente influenciada por comportamentos de festividade e práticas supersticiosas realizadas por aqueles que fazem parte deste cenário, em especial os torcedores.

O terceiro ritual mais relatado durante as entrevistas foi o "consumo de bebidas alcoólicas". Vale ressaltar que esta é uma prática comum em vários outros ambientes distintos do futebol, como praias, eventos de música e demais momentos que estão relacionados ao tempo do não trabalho. No entanto, é preciso chamar a atenção para o fato de que este hábito tem se tornado cada vez mais comum entre os torcedores de futebol, principalmente antes e após as partidas. Muitos torcedores antecipam sua chegada aos estádios para encontrarem amigos e consumir bebidas alcoólicas, como relatado nas falas a seguir:

"Chego cedo para juntar os amigos e tomar uma cerveja gelada". $\left[\mathrm{T}_{\mathrm{sp}(31)}\right]$

"[...] chegar cedo para bater um papo com os amigos comentando sobre quem vai jogar, quem deixa de jogar... [...] a gente se senta, toma uma cervejinha e fica conversando até $o$ jogo começar". $\left[\mathrm{T}_{\mathrm{sc}(29)}\right]$

"Bem, eu chego umas três horas antes e fico bebendo". [ $\left.\mathrm{T}_{\text {nau(7) }}\right]$

Após o término das partidas de futebol, alguns torcedores revelaram continuar o consumo das bebidas alcoólicas, principalmente quando o time alcança a vitória, como evidenciado nos discursos abaixo: 


\begin{abstract}
"Se vitória, comemorar com uma saideira, independente do resultado, da significância, esticar um pouquinho mais". [T $\left.{ }_{\text {sp(31) }}\right]$

"Eu venho bebemorar, independente de resultados. Claro que a euforia maior é quando ele sai vencedor". [ $\left.{ }_{\mathrm{sc}(30)}\right]$

“Ceralmente quando o náutico perde, aí volta pra casa triste... Mas quando ganha, continuar a bebedeira, ir pra algum bar em Recife mesmo ou na casa de alguns $\operatorname{amigos}[\ldots]^{\prime \prime} \cdot\left[\mathrm{T}_{\text {nau( } 7)}\right]$
\end{abstract}

O hábito de consumir bebidas alcoólicas no contexto do futebol também foi evidenciado em outros estudos (LIMA; MOURA; ANTUNES, 2015; RODRIGUES; SARRIERA, 2015), que revelaram ser esta uma prática comum, principalmente entre os torcedores jovens do sexo masculino como parte da celebração do espetáculo esportivo. De acordo com Flecha e Pontelo (2015), o futebol é considerado uma atividade de lazer masculinizada, ligado aos amigos que se encontram nos estádios e que chegam com antecedência ao início dos jogos para cultivar o hábito de beber. Realidade esta confirmada pelas observações realizadas neste estudo. Como a coleta de dados iniciava umas três horas antes do início da partida, ao chegar aos estádios, foi possível observar grupos de amigos reunidos ao redor do carro, escutando músicas, conversando, fazendo churrasco e consumindo bebidas alcoólicas. Ao conversar com os torcedores, verificou-se que a adoção destas práticas era uma maneira de relaxar e esquecer a vida estressante vivida durante a semana.

Segundo Elias e Dunning (1992) e Le Breton (2000), o consumo de drogas (lícitas e ilícitas), entre elas o álcool, possibilita o extravasamento das tensões que são reprimidas durante a vida rotineira, induzindo o indivíduo a um estado de espírito relaxado para desfrutar momentos de festividades como, por exemplo, o futebol. Romera e Reis (2009) ressaltam que as primeiras doses de álcool permitem um efeito sociabilizador e as doses seguintes, quando consumidas além do limite, podem incitar a violência e agressividade, levando o indivíduo a adotar determinados comportamentos de risco. A investigação de Reis e Lopes (2016) evidenciou que as drogas e as bebidas alcoólicas representam um dos motivos que contribuem para a violência em dias de jogos. Por outro lado, torna-se necessário considerar que o uso abusivo do álcool pelos espectadores de futebol não pode constituir o único fator gerador da violência, pois, segundo Reis (2012) e Murad (2013), a violência tornou-se um problema complexo e multifatorial existente em toda a sociedade, nos seus diferentes tempos e espaços, e decorrente dos mais diferentes fenômenos.

Ao mesmo tempo, é preciso considerar que o consumo de bebidas alcoólicas nos estádios de futebol também está relacionado com o processo da indústria cultural. A este respeito, Bertolo e Romera (2011) enfatizam que o álcool é facilmente comercializado nos ambientes futebolísticos e as propagandas ligadas a este produto são constantemente visualizadas pelos torcedores a partir dos meios de comunicação (televisão, outdoors, camisas do time, etc.), com o intuito de patrocinar o espetáculo e também de apresentar uma relação positiva do consumo do álcool com os momentos de lazer. O número de 
referências visuais expostas aos torcedores contribui para o seu consumo por passar imagens de satisfação, relaxamento, diversão e socialização.

O quarto e último ritual encontrado está relacionado ao ato de "torcer/comemorar" durante e após as partidas de futebol. Várias foram as práticas torcedoras apontadas pelos torcedores, principalmente no momento do gol, no qual é nítido a explosão da emoção. Além disso, essa emoção é compartilhada até com pessoas desconhecidas, que se tornam amigas mesmo que de maneira momentânea, como indicado nas falas abaixo:

"Durante um gol é uma explosão de alegria, é grito, é pulo, varias coisas". [ $\left.\mathrm{T}_{\mathrm{sp}(25]}\right]$

"Fez um gol, só torcer, só vibrar, gritar... não posso ficar calado ne?". [ $\left.\mathrm{T}_{\text {sc(15) }}\right]$

"Vou abraçar as pessoas e acabo abraçando muito forte, batendo nas costas...". $\left[\mathrm{T}_{\text {nau(22) }}\right]$

O "torcer" é uma expressão que se originou a partir da palavra "torcedor", quando as mulheres torciam seus lenços ao ficarem nervosas durante os momentos decisivos de uma partida de futebol, por volta da década de 30 (HOLANDA, 2014). De acordo com Marra (2012), uma partida de futebol transformou-se em um espetáculo não apenas visual, mas também sonoro, sendo possível perceber uma pluralidade de gritos que partem de diferentes torcidas organizadas e de torcedores independentes. O momento do gol é marcado por grande sonoridade no estádio, principalmente quando há uma maior rivalidade com o time adversário, servindo de ânimo e combustível para estas torcidas.

O estudo de Origuela e Silva (2015) procurou identificar e analisar os significados de assistir aos jogos de futebol no estádio e verificou que esta atitude traz uma oportunidade de expressão distinta das de outros momentos da vida cotidiana, com gritos e cantos de hino, uma vez que os participantes são absorvidos pelo espetáculo e levados pela emoção do momento. Nas observações realizadas neste estudo, foi possível perceber as manifestações coletivas que envolvem o estádio de futebol, local no qual inúmeros sentimentos são exteriorizados, do início ao final da partida, por meio de falas, gritos, danças, músicas. O torcer, na verdade, acaba sendo uma certeza pessoal de que o torcedor é capaz de interferir no jogo e no resultado final a partir das práticas adotadas. Por outro lado, Galvão e Galvão (2016) enfatizam que, apesar da energia positiva que os torcedores passam aos jogadores no momento do jogo, nem sempre a presença da torcida no estádio influencia no resultado final.

Quando o time vence, a comemoração é inevitável e pode se manifestar de diferentes maneiras, como indicado a seguir:

"A gente só faz comemorar... chego em casa, a gente solta fogos". $\left[\mathrm{T}_{\mathrm{sc}(9)}\right]$

"Após o jogo é engraçado... Se a gente perde eu fico derrubada e é terrível. Mas se a gente ganha, você quer sair mais, quer se divertir mais, quer se confraternizar mais". $\left[\mathrm{T}_{\text {nau(32) }}\right]$ 
Na realidade, o torcedor espera sempre a vitória do seu time, não importando se os jogadores tiveram um bom desempenho no jogo. A derrota geralmente é justificada pelo acaso ou pela ajuda do juiz (TOLEDO, 2000). $\mathrm{O} \mathrm{T}_{\mathrm{sp}(15)}$ costuma entrar nas redes sociais para tirar vantagem da vitória do seu time, como descrito na sua fala:

"Ir pra rede social perturbar todo mundo ne? Ir pra rede social, gritar gol pra incomodar os outros ne? Torcedor do Sport é isso".

Neste olhar, as redes sociais se tornaram uma ferramenta na qual os torcedores podem expor suas opiniões, paixões, canalizar sentimentos e emoções sobre o esporte, além de criar um espaço de sociabilidade, onde podem ser discutidos inúmeros assuntos que não necessariamente sejam apenas sobre o futebol.

Os diversos rituais presentes no futebol fazem parte do cenário esportivo e do espetáculo que marcam a identidade de um povo apaixonado pelo seu time. Assim, contemplar esse cenário ajuda a entender a dinâmica que está presente entre os torcedores e as diversas emoções vivenciadas por estes atores sociais.

\section{CONSIDERAÇÕES FINAIS}

Este estudo buscou identificar e analisar os símbolos e os rituais dos torcedores do futebol dos três principais times de Pernambuco: Sport, Santa Cruz e Náutico. Em relação aos símbolos, observaram-se distintos elementos simbólicos representativos de cada time. No Sport, o símbolo mais indicado foi o Leão, mascote que representa a força e bravura do animal mais poderoso da selva. E para os torcedores do Santa Cruz e do Náutico, as cores tricolores e alvirrubras, respectivamente, foram os símbolos de maior destaque. Os símbolos mencionados pelos torcedores são considerados sagrados e carregam uma história e relações de significação características de cada clube. A importância destes símbolos para os torcedores é vital, motivante e demonstra o amor que eles sentem pelo time ao vestir ou portar algum objeto que represente o clube.

Paralelamente aos símbolos, foram identificados alguns rituais que estavam presentes antes, durante e após o espetáculo futebolístico, tais como: a presença da oração, dos comportamentos/práticas supersticiosas, o hábito de consumir bebidas alcoólicas com os amigos e o ato de torcer/comemorar, principalmente nos momentos dos gols e/ou com a vitória do time. Estes rituais revelaram uma dinâmica repetitiva dos torcedores, realizada nos momentos distantes das suas atividades cotidianas, que os libertam das tensões provenientes do dia a dia. Ao mesmo tempo, tais rituais possuem uma dimensão simbólica sobre o cotidiano dos torcedores, capaz de influenciar seus comportamentos e atitudes.

Estudar este cenário de símbolos e rituais dos torcedores de futebol pernambucano permitiu discutir os sentimentos e as emoções que estão presentes no campo de jogo, além de apresentar uma realidade que movimenta a dinâmica destes sujeitos nos ambientes esportivos e o impacto que estas questões possuem na sociedade e na área da educação 
física. No entanto, é importante considerar as limitações desta investigação: foi evitado o comparecimento do pesquisador aos estádios em dias de jogos de Clássico devido às dificuldades oriundas da violência ligada ao futebol no estado de Pernambuco. Sugere-se a realização de novas investigações, considerando a relevância das discussões deste tipo no campo de estudos socioculturais da Educação Física com o intuito de apontar outras realidades que influenciam o comportamento dos torcedores.

\section{REFERÊNCIAS}

ALVES, Rogério Othon Teixeira et al. "O clássico dos clássicos" das alterosas mineiras: a invenção da rivalidade futebolística entre Athletico e Palestra. Revista Brasileira de Educação Física e Esporte, São Paulo, v. 30, n. 3, p. 723-741, jul./set. 2016.

ANDRADE, Homero. A princesa e os touros: futebol, signos, símbolos e identidades culturais. Revista Homem, Espaço e Tempo, ano 2, n. 2, p. 55-73, set. 2008.

BANKS, Marcus. Dados visuais para pesquisa qualitativa. 1. ed. Porto Alegre: Artmed, 2009. BARDIN, Laurence. Análise de conteúdo. Lisboa: Edições 70, 2009.

BONIN, Ana Paula Cabral et al. A transmissão radiofônica de jogos de futebol: a incoerente gratuidade de um espetáculo esportivo? Revista Brasileira de Ciências do Esporte, v. 38, n. 2, p. 186-193, 2016.

BRANDÃO, Lucas de Esquivel Dias et al. Os mamíferos representados como mascotes dos times brasileiros de futebol. In: Encontro Regional de Ensino de Biologia. 3., Juiz de Fora. Anais do Encontro Regional de Ensino de Biologia. Juiz de Fora: UFJF, 2015.

DAMIANI, Erasmo Marcelo. Superstição no esporte. 2005. 122 f. Dissertação (Mestrado em Educação Física). Programa de Pós-Graduação em Educação Física, Universidade Federal de Santa Catarina, Florianópolis, 2005.

DAOLIO, Jocimar. Futebol, cultura e sociedade. Campinas: Autores Associados, 2005.

DEBORD, Guy. A Sociedade do Espetáculo. E-book digitalizado por Coletivo Periferia e e-Books Brasil, 2003. Disponível em: < http://www.ebooksbrasil.org/adobeebook/ socespetaculo.pdf $>$. Acesso em: 06 de junho de 2016.

DURAND, Gilbert. As Estruturas Antropológicas do Imaginário. São Paulo: Martins Fontes, 1997.

ELIAS, Nobert; DUNNING, Eric. A Busca da Excitação. 1 ed. Lisboa: DIFEL, 1992.

ELIADE, Mircea. Imagens e Símbolos: Ensaio sobre o simbolismo mágico-religioso. São Paulo: Martins Fontes, 1991.

. Tratado de história das religiões. 3 ed. São Paulo: Martins Fontes, 2008.

. O sagrado e o profano: a essência das religiões. 3 ed. São Paulo: WMF Martins Fontes, 2011.

FLECHA, Angela Cabral; PONTELLO, Mathaeus Levy. Comportamento do torcedor do futebol. PODIUM Sport, Leisure and Tourism Review, São Paulo, v. 4, n. 2, p. 72-87, mai./ago. 2015. 
FONTANELLA, Bruna José Barcellos; RICAS, Janete; TURATO, Egberto Ribeiro. Amostragem por saturação em pesquisas qualitativas em saúde: contribuições teóricas. Cadernos de Saúde Pública, Rio de Janeiro, v.24, n.1, 2008.

GALVÃO, Nadielli Maria dos Santos; GALVÃO Nadianni Maria dos Santos. Jogo bom e arquibancada cheia: uma análise da relação entre desempenho em campo e atração de público em jogos de futebol. Revista Brasileira de Futsal e Futebol, São Paulo, v. 8, n. 28, p.52-58. Jan./abr. 2016.

GIULIANOTTI, Richard. Sociologia do futebol: dimensões históricas e socioculturais do esporte das multidões. São Paulo: Nova Alexandria, 2010.

HOLANDA, Bernardo Borges Buarque de. The fan as actor: the popularization of soccer and Brazil's sports audience. Soccer \& Society, Abingdon, v. 15, n. 1, p. 8-18, 2014.

LE BRETON, David. Passions du risque. Paris: Métailié, 2000.

. As paixões ordinárias: antropologia das emoções. Rio de Janeiro: Vozes, 2009.

LIMA, Rafael Leal de; MOURA, Diego Luz; ANTUNES, Marcelo Moreira. Ritos e sociabilidades no torcer coletivo: um estudo etnográfico em uma torcida do flamengo. Licere, Belo Horizonte, v.18, n.1, p. 136-156, mar. 2015.

MACHADO, Murilo d'Almeida. O êxtase no futebol: a comunicação ritual e suas experiências sensoriais. 2005. 289 f. Tese (Doutorado em Multimeios). Programa de Pós-graduação em Multimeios da UNICAMP, Universidade Estadual de Campinas, Campinas, 2005.

MARCONI, Marina de Andrade; LAKATOS, Eva Maria. Fundamentos de metodologia científica. $7^{a}$ ed., São Paulo: Atlas, 2010.

MARRA, Pedro Silva. "Vou ficar de arquibancada pra sentir mais emoção" - uma proposta de pesquisa acerca das sonoridades do futebol. Contemporânea/Comunicação e Cultura, v.10, n. 1, p. 175-193, jan./abr. 2012.

MINAYO, Maria Cecília de Souza. O desafio do conhecimento: pesquisa qualitativa em saúde. São Paulo: Hucitec, 2007.

MONTEIRO, M. G. Políticas públicas para a prevenção dos danos relacionados ao consumo de álcool. Revista Epidemiologia e Serviços de Saúde, v. 25, n. 1, p. 171-174, 2016.

MURAD, Mauricio. Práticas de violência e mortes de torcedores no futebol brasileiro. Revista USP, n. 99, p. 139-152, 2013.

ORIGUELA, Milena Avelaneda; SILVA, Cinthia Lopes da. Lazer e futebol: o torcedor no estádio. Coleção Pesquisa em Educação Física, São Paulo, v. 14, n. 1, p. 81-88, 2015.

REIS, Heloisa Helena Baldy dos. Lei geral da copa, álcool e o processo de criação da legislação sobre violência. Movimento, Porto Alegre, v. 18, n. 01, p. 69-99, jan./mar., 2012.

REIS, Heloisa Helena Baldy dos; LOPES, Felipe Tavares Paes. O torcedor por detrás do rótulo: caracterização e percepção da violência de jovens torcedores organizados. Movimento, v. 21, n. 3, 693-706, jul./set. 2016.

RODRIGUES, Anelise Lopes; Sarriera, Jorge Castellá. Padrões de consumo de álcool e drogas em jovens torcedores de futebol. Revista Psicologia: Teoria e Prática, São Paulo, v. 17, n. 3, p. 52-65, set./dez. 2015. 
ROMERA, Liana Abrão; REIS, Heloisa Helena Baldy dos. Uso de álcool, futebol e torcedores jovens. Motriz: Revista de Educação Física, Rio Claro, v.15, n.3, p.541-551, 2009.

SEGALEN, Martine. Ritos e Rituais Contemporâneos. Rio de Janeiro: FGV, 2002.

SIMÕES, Antonio Carlos; CONCEIÇÃO, Paulo Felix Marcelino. Gestos e expressões faciais de árbitro, atletas e torcedores em um estádio de futebol: uma análise das imagens transmitidas pela televisão. Revista Brasileira de Educação Física e Esporte, São Paulo, v.18, n.4, p.343-61, out./dez. 2004.

SOUZA, Juliano de; MARCHI JÚNIOR, Wanderley. As linhagens da sociologia do futebol brasileiro - um programa de análise. Movimento, Porto Alegre, v. 23, n. 1, p. 101118, jan./mar. 2017.

SPRADLEY, James. Participant observation. Fort Worth: Harcourt Brace College Publishers, 1980.

TEIXEIRA, Rosana da Câmara. Torcidas jovens cariocas: símbolos e ritualização. Esporte e Sociedade, n. 2, mar./jun. 2006.

TOLEDO, Luiz Henrique. Lógicas no Futebol: Dimensões simbólicas de um esporte nacional. 2000. 348 f. Tese (Doutorado em Antropologia). Programa de Pós-Graduação em Antropologia Social, Universidade de São Paulo, São Paulo, 2000.

TURNER, Victor. O processo ritual. Petrópolis: Vozes, 1974.

Recebido em: fevereiro/2017 Aprovado em: junho/2017 